until a Committee Meeting was called on I6 July 1945. It was then decided to recommence its activities.

The President concluded by saying that they were the only body which could call together all British glaciologists under one roof and, incidentally, were unique as being the only association of its kind in the world. Because of this he considered it to be the platform on which all matters of interest to British glaciologists should be discussed.

2. The President put forward the Committee's proposal that the name of the Association should be changed to "British Glaciological Society" for reasons already circulated to members. The proposal was seconded by Dr. N. E. Odell and carried unanimously. On the question whether members of the Society would prefer to remain "members" or to be known as "fellows" it was unanimously agreed to retain the designation "members."

3. The President reported that Professor Debenham had resigned from the Committee. All the places on the Committee had been filled by co-option and he offered to the Meeting for re-election the names of the three co-opted members: Lt.-Cdr. A. R. Glen, R.N.V.R., Dr. Brian Roberts and Mrs. Graham Rowley.

The proposal was seconded by Dr. N. A. Mackintosh and carried unanimously.

4. The President reported that owing to uncertainty of private plans he wished to hold over the appointment of an Honorary Secretary for the time being. This was agreed to.

5. The President reported that when the work of the Society lapsed in $194 \mathrm{I}$ there were about 120 members. From the circular sent out to those members 57 replies had so far been received, 49 of these being acceptances. 20 new names had been forwarded to him as suggested new members, and of these so far 7 had joined.

The President pointed out that the Annual General Meeting had been called before the time laid down in the regulations. Colonel Andrew Croft proposed that the meeting should indemnify the Committee. Squadron-Leader Dunlop-Mackenzie seconded the proposal, which was carried unanimously.

The Meeting then discussed the suggestions for papers sent in by members and proposals for increasing the general usefulness of the Society.

6. The President asked Dr. N. E. Odell, in accordance with the Society's accepted practice, to take the Chair for the reading of the papers.

Inst. Lt.-Cdr. R. Moss, R.N., and Lt.-Cdr. A. R. Glen, D.S.C., R.N.V.R., then read the papers which, together with the discussion, are reported below.

\title{
INVESTIGATIONS ON ICE DURING THE WAR
}

\section{Instructor Lieutenant-Commander R. Moss, R.N.}

LT.-CDR. Moss said that the problem of icing up had become very acute during the war because of the necessity for the North Russian convoys to steam for many days in regions of high humidity and low temperature. This resulted in great accumulations on decks and superstructure and interfered with accurate navigation. As yet no really satisfactory method of overcoming this problem had been devised. 
The Russians had used aircraft for investigating sea ice for many years but detailed results had not been made available. Coastal Command had also developed aerial reconnaissance on a large scale, but results had not yet been fully worked out from the glaciological, as opposed to the purely practical, point of view.

The lecturer thought that the British Glaciological Society should take a leading part in the continuation of this work and in making it available to all who needed the resulting information.

A number of aerial photographs of ice floes showed remarkable variations in the degree of whiteness of the ice, and Lt.-Cdr. Moss suggested that there might be the possibility that the less white patches indicated promising lanes for navigation. He believed that one slow-flying aircraft, with its more nearly vertical view from a greater height, would cover a very wide field of view and would be much more valuable than conning from the crow's nest.

The lecturer showed photographs of the progressive "break up" of ice, the floes assuming a more or less rectangular shape which in course of time became sub-angular or rounded. In spite of the uniform size of the large majority of floes in the localities depicted, a few were much larger than the rest and, being whiter, suggested again, but without proof as yet, that the increased whiteness meant decreased thickness and thus provided the much desired key to a lead-so necessary for the navigation of ice pack.

Lt.-Cdr. Moss concluded with photographs of "ice lanes" and drift accumulations on land. These showed that in the investigation of the causes of snow and ice phenomena aerial observation was of great assistance.

\section{Lieutenant-Commander A. R. Glen, D.S.C., R.N.V.R.}

Lt.-Cdr. Glen said he wished to mention two aspects of glaciological research which had been stimulated by the war. First the study of ice conditions in the Arctic Ocean, particularly the North Atlantic and the Barents Sea. Previously no systematic study of the ice-edge or its changes of position throughout the year had been made, because without the aid of aircraft the distance to be covered at regular and frequent intervals would be too great, and the use of aircraft was too expensive a method without a compelling reason. This reason was supplied on the establishment of the northern sea route to Russia in 1942 when it became necessary to make a detailed study of the sea ice and its limits in the Spitsbergen Channel. The Luftwaffe were present in great strength in northern Norway and from their bases were inflicting heavy losses on our convoys. Security could be increased by diverting them into the fogs and mists farther north.

Sorties to Spitsbergen were flown at the beginning and end of April 1942 and repeated at two- or three-weekly intervals until October. These covered the ice limits between Jan Mayen and Bear Island and also those east to Novaya Zemlya and the White Sea. Most flights were carried out in unfavourable weather which included much icing, fog and winds in excess of roo miles per hour. To have made these under war-time conditions must rank among the more remarkable achievements of the R.A.F.

A system of recording the type and quantity of ice was evolved in conjunction with the Naval Meteorological Branch and provided for the first time a study of the location and movement of the sea ice-edge from Denmark Strait to the White Sea between March and 
October 1942. The fact that $1941-42$ had been an exceptionally bad ice year made the observations of unusual interest. These records were being examined, together with those made until 1944 , and would be published in 1946 .

The second aspect was that of icing of aircraft at low temperatures. Hitherto meteorological handbooks had provided the reassuring information that serious icing need not be expected below $-18^{\circ} \mathrm{C}$. It was surprising that this minimum level for serious icing hadbeen maintained since glaciological research had shown that on occasions a hoar-frost recorder had shown considerable accretions of heavy glazed ice in addition to light flakey rime at temperatures of $-35^{\circ}$ or $-40^{\circ} \mathrm{C}$. For example, on the first sortie to Spitsbergen in April 1942 it had been necessary to try to climb through heavy strato-cumulus cloud. The air temperature had fallen below $-40^{\circ} \mathrm{C}$., but despite this heavy icing was encountered and cloud was only finally cleared at 8500 feet. This may have been due to super-cooled water droplets, for the accretion was of a glazed, black elastic type which built up quickly and caused considerable trouble to the pulsating edge de-icers and the engines. On other sorties, similar conditions had been encountered in temperatures down to $-29^{\circ} \mathrm{C}$., particularly over or near the edge of the sea ice in a zone of heavy icing fog. Evidence from other pilots confirmed icing at temperatures as low as $-45^{\circ} \mathrm{C}$., and it seemed therefore that there were enough reports of heavy icing being encountered at temperatures well below the present minimum level to warrant an effort being made to investigate this problem.

In conclusion, Lt.-Cdr. Glen stated that what he had said was the barest summary of two aspects of those activities of Coastal Command aircraft which bore some relation to the interests of the Society. A full account of this high latitude flying was to be given in a paper to be read to the Royal Geographical Society and he did not wish to anticipate this account, except to endorse strongly the suggestion made by Squad.-Leader Dunlop-Mackenzie that the Society should try to work in close association with the Service Departments and in particular with the Air Ministry.

\section{DISCUSSION}

In the discussion which followed Commander C. R. Burgess, R.N., said that he thought the Navy could help in supplying reports from vessels in ice-frequented seas, if the Society would set out the kind of information required.

On the question of low-temperature icing, Mr. G. ManLEy suggested that in the Arctic the super-cooling of liquid drops might go farther than the studies in the temperatures indicated.

Mr. L. Bonacina said that at low temperatures the relative humidity was always high, though the actual vapour content of the air was small and that this undoubtedly bore on the problem.

Flt.-Lt. R. Hamilton said that the Air Ministry figures were derived from experience, which showed that serious icing was not encountered below $-18^{\circ} \mathrm{C}$., except in the case of cumulonimbus. The low temperatures mentioned by Lt.-Cdr. GLEN were not confined to Arctic regions; such temperatures were found at higher levels in temperate regions where aircraft had flown without encountering serious icing.

Lt.-Cdr. GLEN replied that between $73^{\circ}$ and $76^{\circ} \mathrm{N}$. icing had been encountered at air temperatures which fell below $-40^{\circ} \mathrm{C}$. at heights between 1500 and 8500 feet. Similar heavy icing south of Iceland had been reported in temperatures below $-45^{\circ} \mathrm{C}$. at 23,000 feet and also icing in somewhat similar temperatures off East Greenland. These examples seemed to dispose of the contention that heavy icing was not experienced at these temperatures.

Mr. G. Seligman thought that the problem of icing up depended rather upon relative humidity 
than on temperature. In this connection in 1940 he had been invited by the Air Ministry to give advice on a research on the icing of aircraft and he thought by now these results must be available.

In connection with sea ice, the Reverend W. L. S. FLeming said that before the war he had hoped that more detailed information could have been obtained from the whaling companies about the distribution of icebergs and sea ice in the Southern Ocean. With the resumption of whaling it should now be possible to obtain this information. It would be necessary to adopt a satisfactory method of recording it.

Dr. B. ROBERTS stated that the Danes had formulated standard methods of reporting and mapping sea ice; he hoped that it would be possible for the Society to keep in close touch with them with a view to reaching international agreement about the general use of the improved methods of reporting developed during the war.

Cdr. Burgess added that the Admiralty had ice charts for all the Arctic and the extreme North Atlantic showing the average limit over the last twenty or thirty years, and also the extreme limit. Danish reports as well as Russian and captured German atlases had been used during the war.

Lt.-Cdr. Glen stated that a system of reporting had been improvised during the first sortie in March 1942, by which the type of ice was recorded by letter indices and its quantity in tenths of sea covered. This was later modified and worked satisfactorily, except that examination of the photographs revealed that the observers exaggerated the amount of sea covered by about threetenths.

Dr. RoBERTs said that the Polar Research Institute, when trying to work out a satisfactory method of reporting sea ice, had made use of vertical air photographs taken of the pack ice off East Greenland. The estimates made by experienced polar voyagers in one photograph varied between five- and eight-tenths of sea covered by ice, when the amount by actual measurements was seven-tenths. These estimates from photographs showed much greater variations than when meteorologists used a similar scale for estimating cloud cover.

Lt.-Cdr. GLen added that it was only at the beginning that there had been a tendency to overestimate the amount of ice and to underestimate the amount of water, especially when the ice had been much broken up. With increased experience the observations became much more accurate.

With reference to the ice lanes, Lt.-Cdr. E. B. RHEAD said that these only appeared after gales and lay in the direction of the wind. He always expected to find them if there was a strong wind blowing off the ice.

At the conclusion of the meeting Dr. Odell proposed a vote of thanks to the speakers and those who had contributed to the discussion, which was seconded by Mr. Seligman, who also thanked Cdr. Burgess for attending the meeting and for giving much assistance in its preparation.

\section{GENERAL MEETING}

held at the Geographical School, Cambridge, on Friday, 26 April 1946 at 8 p.m.

13 members and 39 visitors were present

The President said that the Minute book containing the Minutes of the last General Meeting (22 October 1945) would be left available for inspection and in the absence of comment would be signed at the end of the meeting.

I. President's Report. The President said that the membership of the Society had reached roo and that he hoped shortly to enrol several new Canadian members.

The Snow Survey of the British Isles would be recommenced next winter. The cooperation of Dr. E. L. Hawke and other members of the Royal Meteorological Society had been secured for this work. 